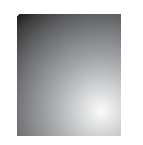

\title{
A Incorporação do EMpreendedorismo no SEtor Público: Reflexões baseadas no conteXto brasileiro
}

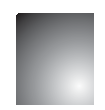

\author{
The Incorporation of Entrepreneurship in the Public Sector: \\ reflections based on brazilian context
}

\author{
Josiel Lopes Valadares \\ Doutorando em Administração da Universidade Federal de Lavras (UFLA). Professor na Faculdade de Administração e Ciências \\ Contábeis (FACC). Viçosa, MG. Brasil.E-mail: adm_josiel@yahoo.com.br
}

\section{Magnus Luiz Emmendoerfer}

Pós-Doutorando em Ciências da Administração, Universidade do Minho, Portugal. Docente e Líder do Grupo de Pesquisa em Gestão e Desenvolvimento de Territórios Criativos no Departamento de Administração e Contabilidade na Universidade Federal de Viçosa.

Viçosa, MG. Brasil.E-mail: magnus@ufv.br

\section{Resumo}

Este ensaio visa ampliar o debate sobre a incorporação do tema Empreendedorismo no Setor Público (ESP) por meio da revisão de literatura sobre o caráter reflexivo que se deve ter ao transpor conceitos do setor privado para o público. Compreendeu-se que é necessária uma discussão crítica acerca do processo de apropriação desse tema no Brasil para que seja adequadamente coerente e contextualizado. Observou-se que a administração pública brasileira é marcada por um modelo híbrido de gestão, no qual práticas patrimonialistas, burocráticas e gerenciais coexistem, tornando a adaptação do empreendedorismo complexa. Portanto, é preciso ter cautela com as expectativas exageradas em relação a esse tema na administração pública brasileira, pois, há inúmeras limitações que vão de encontro à sustentabilidade de governos democráticos.

Palavras-chave: Comportamento Empreendedor. Governo. Gestão Pública. Organizações. Inovação.

\begin{abstract}
This essay aims seeks to broaden the debate on the incorporation of the theme Entrepreneurship in the Public Sector (EPS) through the literature review on the reflective character to be taken to transpose concepts from the private sector to the public sector. It was understood that needs a critical discussion on the process of appropriating that theme in Brazil. It was observed that the Brazilian Public Administration is marked by a hybrid model of administration, in which patrimonial practices, bureaucratic and managerial coexist, making the complex adaptation of entrepreneurship. Therefore, we must be wary of exaggerated expectations regarding this theme in Brazilian Public Administration, as have several limitations that meet the sustainability of democratic governments.
\end{abstract}

Keywords: Entrepreneurial Behavior. Government. Public Management. Organizations. Innovation. 


\section{INTRODUÇÃo}

As mudanças ocorridas no setor público nos últimos anos têm promovido o aumento das expectativas de reforço de sua modernização e o interesse de diversos pesquisadores, como Orborne e Gaebler (1994), Bellone e Goerl (1992), Moore (1995), Morris e Jones (1999), Caruana et al., (2002), Barnier e Hafsi (2007), Currie et al. (2008), Klein et al. (2010), Diefenbach (2011) e Meynhardt e Diefenbach (2012) em entender os possíveis desdobramentos, talvez contraditórios, que essa modernização acarretou ao Estado. Nas últimas décadas, esse processo de modernização tem sido associado a noções comportamentais e gerenciais, imbuídas de conceitos e práticas, que eram próprias e, até então, restritas à esfera das organizações empresariais.

O empreendedorismo é uma dessas noções que tem sido empregada no setor público, como forma de criar valor para os cidadãos. Essa noção sinaliza a necessidade dos gestores nas organizações públicas desenvolverem uma Orientação Empreendedora (OE) voltada para a capacidade de se adequar e de inovar frente às novas demandas do setor público (MILLER, 1983; COVIN; SLEVIN, 1991; LUMPKIN; DESS, 1996). Ao desenvolver essa orientação, as organizações públicas poderiam tornar-se aptas a promover uma cultura de mudança que em seu âmago estaria a propagação de um espírito empreendedor no contexto da administração pública como na perspectiva adotada por autores que defendem a manutenção de uma cultura do management no contexto das organizações públicas. Ressalta-se que apesar de o conceito de Orientação Empreendedora ser bastante debatido e discutido na literatura especializada, a discussão sobre o tema empreendedorismo aqui realizada será ampliada pela compreensão de diversas abordagens relacionadas a esse tema.

Este trabalho parte de discussões sobre as abordagens do empreendedorismo: a) econômica (SCHUMPETER, 1954; BAUMOL, 1968; KIHLSTROM; LAFFONT, 1979); b) comportamental (STEVENSON; JARILLO, 1990; COVIN; SLEVIN, 1991; CUNNINGHAN; LISCHERON, 1991; BYGRAVE, 1993); corporativa (MILLER; FRIESEN, 1982; BURGELMANN, 1983; PINCHOT, 1985; CORNWALL; PERLMAN, 1990; HASHIMOTO, 2009; DIEFENBACH, 2011); e também daqueles que aplicam os conceitos dessa escola no setor público (ROBERTS; KING, 1991; OSBORNE; GAEBLER, 1992; MORRIS; JONES, 1999; KEARNEY et al. 2007; KLEIN et al., 2010; DIEFENBACH, 2012; EMMENDOERFER; VALADARES, 2014).

Enquanto no setor privado as contribuições $e$ os desafios do empreendedorismo têm sido extensivamente estudados, no setor público, sobretudo no Brasil, estudos sobre esse assunto são difíceis de serem encontrados. Possíveis causas dessa limitada produção nacional seriam: o assunto é recente no Brasil; há poucas evidências verificadas cientificamente; e os setores público e privado apresentam diferenças importantes tornando a transposição de práticas complexa e, em algumas situações, inadequadas. (BERGUE, 2011; DIENFEBACH, 2011)

Segundo Bergue (2008, p. 2), "[...] o atual cenário da administração pública brasileira revela forte e sem precedente inclinação para adição de práticas gerenciais usuais no campo gerencial". Esse movimento apresenta-se em forma de duas perspectivas: a) oferta - esforços exógenos que promovem e estimulam a transferência, como as influências dos conceitos estrangeiros; e, b) demanda - a busca das organizações públicas por inovações gerenciais, como recurso de legitimação e sobrevivência. No entanto, a apropriação de técnicas gerenciais no setor público apresenta algumas limitações significativas.

Sobre isso, Bergue (2011) observou que essa prática tem sido denotada de um caráter parcial, na qual a ênfase passa a ser no formato e não no conteúdo. Dessa forma, o reduzido esforço de reflexão crítica (em que os modelos são importados de casos de sucesso de outros países, ou, quando adaptado, preservando seu formato original) favorece a coexistência de elementos e práticas gerenciais tradicionais e inovadoras na administração pública.

Estudar o empreendedorismo no setor público do Brasil torna-se uma oportunidade de pesquisa na área, a qual é movida por uma inquietação: Quais cuidados são necessários para a incorporação do conceito de empreendedorismo na administração pública brasileira? Frente a tal questionamento, este ensaio busca ampliar o debate sobre a incorporação do empreendedorismo no setor público brasileiro através da revisão de literatura e de reflexões pontuais sobre o caráter reflexivo que se deve ter ao transpor conceitos do setor privado para o público. Nesse sentido, 
busca-se analisar como o empreendedorismo tem sido discutido no setor público e quais estratégias seriam necessárias para a sua incorporação na administração pública preservando o caráter emancipatório, social e político dela.

A sua operacionalização ocorreu em três seções estruturantes, além desta introdução. A primeira traz uma revisão acerca do empreendedorismo e suas principais abordagens. A segunda seção busca definir a noção de empreendedorismo nas organizações públicas. A terceira e principal parte traz reflexões pontuais acerca da incorporação do empreendedorismo público no contexto brasileiro.

\section{Definindo o Empreendedorismo E suas Principals Perspectivas}

O primeiro sentido da palavra empreendedorismo surge do latim imprehendere que significava um modo "[...] abrangente do ser empreendedor, ou seja, é ela que informa o componente indubitável da atividade empreendedora. Imprehendere tem como significado prender nas mãos, assumir e fazer" (BOAVA; MACEDO, 2011, p. 4). Em outras palavras, empreendedorismo tinha a ver com ações comprometidas, engajadas e que rompessem com a atitude natural das pessoas. No entanto, com os avanços da sociedade e do capitalismo, historicamente o empreendedorismo a partir dos séculos XIX e XX passa a ser ressignificado como uma atividade que promove crescimento, transformando o empreendedor no representante do objeto de manutenção e propagação do desenvolvimento econômico. (COSTA; BARROS; CARVALHO, 2011)

Nesse contexto, os autores pioneiros dessa temática foram Richard Cantillon, em 1755, e Jean-Baptiste Say, em 1803 (FILION, 1997). Sadler (2000) indica que o conceito de Cantillon buscou explicar a receptividade ao risco de comprar algo por um preço e vendê-lo em regime de incerteza. Say (1803) apresentado por Filion (1997) sustentou que o empreendedor era capaz de alterar os recursos econômicos de uma área decadente, transformando-a em algo com produtividade e lucratividade elevadas, sendo que ele atuava como o catalisador do desenvolvimento econômico. Tanto na definição de Cantillon (1755) como na de Say (1803), o empreendedor é tomado como um agente tomador de risco (SADLER, 2000). No entanto é através da construção de Joseph Schumpeter que o tema empreendedorismo ganha mais vulto na vida social e inclusive na literatura especializada.

Para o Schumpeter (1954), o empreendedor era tratado de forma peculiar por sua capacidade de criar, inovar e de agregar valor em produtos, processos e serviços, nos quais a inovação era a principal força para criação de novas demandas e riquezas. Esse pesquisador observou que o empreendedor conduzia e criava novas combinações de produção por meio do processo de destruição criativa.

Schumpeter (1954) observou também que o ímpeto para o sistema econômico vem de pessoas de coragem, que arriscam suas fortunas para implementar, inovar, experimentar e expandir novas ideias. Escritores posteriores a Schumpeter (1954), como Higgins (1959) e Baumol (1968), ampliaram a noção de empreendedorismo ao indicarem que esse poderia ser visualizado como causador da substituição de produtos obsoletos por produtos mais inovadores e com maior potencial de lucro. O empreendedorismo para Drucker (1985) é uma forma de intensa mudança, em que o empreendedor é alguém que sempre se apoia nelas para a busca e exploração de novas oportunidades.

A contribuição dos economistas para o conceito de empreendedorismo ressignificou o conceito original que não tinha uma ligação direta com a questão do capitalismo (BOAVA; MACEDO, 2011). É a partir das contribuições dos economistas que o empreendedorismo passou a ser compreendido como um agente de desenvolvimento econômico (SMITH, 1766; BAUMOL, 1968); empreendedores de negócios (HIGGINS, 1959); tomadores de riscos (KIHLSTROM; LAFFONT, 1979); trabalhadores em condições de ambiguidade e incerteza (SADLER, 2000). Isso trouxe grandes implicações para a sociedade e organizações em geral, pois, o empreendedorismo passou a ser uma competência básica para o alcance dos objetivos dos atores presente no mercado. Assim, o empreendedorismo nos moldes econômicos fortaleceu a busca por um pensamento mais liberal $e$ autônomo ressignificando o trabalho $e$ também as relações existentes entre Estado, Mercado e Sociedade. (COSTA; BARROS; CARVALHO, 2011)

Os argumentos de Sadler (2000) corroboram com essa observação, pois, a noção de empreendedorismo apregoada pela abordagem econômica passou a ser 
associada à capacidade da pessoa, enquanto a de empreendedor, de inovar e de poder contribuir para o desenvolvimento local da economia. Essa noção pode ter intensas influências do sistema de produção em vigor na época dos clássicos da economia. Um sistema pautado na noção homos economicus, na qual o indivíduo era considerado uma mera extensão da máquina produtiva, motivado essencialmente por recompensas monetárias.

Na tentativa de compreender o sujeito empreendedor, a abordagem comportamental importou conteúdos de teorias das ciências humanas e sociais visando à descrição de um perfil empreendedor a partir de traços comportamentais (SADLER, 2000). Sob esse enfoque autores como Stevenson e Jarillo (1990), Covin e Slevin (1991), Cunningham e Lischeron (1991) e Bygrave (1993) tentaram descrever tal perfil. Com base nas informações destes, Filion (1997) evidenciou que os empreendedores são resultado de seu ambiente. Este autor constatou que o empreendedor pode ser desenvolvido e que uma cultura empreendedora pode ser um mecanismo catalisador para a formação de um perfil empreendedor. $\mathrm{O}$ ambiente, então, torna-se muito importante na formação do perfil. Se a pessoa cresce em um local onde é incitado a agir de forma empreendedora e a vencer seus desafios, torna-se propenso a desenvolver um perfil empreendedor. Deve-se destacar que no âmago do empreendedor está a busca pela sua autorrealização.

Até a década de 1970, as pesquisas sobre empreendedorismo priorizavam as ações e características individuais dos empreendedores (DRUCKER, 1985; SADLER, 2000). No entanto, a partir de 1980, autores como Miller e Friesen (1982), Burgelmann (1983), Pinchot, (1985), Cornwall e Perlman (1990), Hashimoto (2009) e Diefenbach (2011) desenvolveram pesquisas que compreendessem a noção de empreendedorismo dentro das organizações. Surgiu, assim, o empreendedorismo corporativo, ou seja, o estudo do comportamento empreendedor dentro das organizações (HASHIMOTO, 2009) ou também conhecido como empreendedorismo interno. (EMMENDOERFER; VALADARES, 2011)

Os proponentes da escola corporativa foram Cuninghan e Lischeron (1991), na qual buscaram valorizar as habilidades empreendedoras como variáveis úteis para organizações complexas. Hashimoto
(2009) destaca que os primeiros estudos sobre essa abordagem datam de 1970, com os trabalhos de Peter Drucker e Arnie Cooper. Para Drucker (1985), a responsabilidade das empresas existentes do ponto de vista empreendedor, sobretudo para empresas já bem-sucedidas, é manter-se bem-sucedida no futuro. Tais ideias, conforme já evidenciado, ganharam força na década de 1980, quando as empresas japonesas começaram a invadir o país com seus produtos mais baratos e com melhor qualidade. A partir desse momento, houve um interesse crescente de pesquisadores no estabelecimento de relações entre empreendedorismo e corporações, gerando várias terminologias ao longo do tempo, conforme ilustrado no Quadro 1:

\begin{tabular}{|l|l|l|}
\hline \multicolumn{1}{|c|}{ Autores } & Ano & \multicolumn{1}{c|}{ Terminologia } \\
\hline Biggadike & 1979 & Corporate Venturing \\
\hline Cooper & 1981 & Empreendedorismo intracorporativo \\
\hline Schollhammer & 1981 & Empreendedorismo corporativo interno \\
\hline Burgelman & 1983 & Internal Corporate venturing \\
\hline Miller & 1985 & Orientação Empreendedora \\
\hline Pinchot & 1985 & Intraempreendedorismo \\
\hline Khandwalla & 1987 & Gestão inovadora pioneira \\
\hline Sathe & 1989 & Renovação organizacional \\
\hline Guth e Ginsberg & 1990 & Empreendedor Corporativo \\
\hline Stevenson \&Jarillo & 1990 & Gestão Empreendedora \\
\hline Morse & 1996 & Empreendedorismo em nível de empresa \\
\hline Moris e Sexton & 1996 & Intensidade Empreendedora \\
\hline Dess, Lumpkin\&Covin & 1997 & Estratégia empreendedora \\
\hline Birkinshaw & 1997 & Alianças corporativas \\
\hline Morris et al. & 2008 & Orientação empreendedora \\
\hline Zahra et al. & 2009 & Estimulador de inovação \\
\hline Rauch et al. & 2009 & Empreendedorismo Estratégico \\
\hline
\end{tabular}

Quadro 1: Terminologias do empreendedorismo interno nas organizações

Fonte: Adaptado de Hashimoto (2009, p. 90) com base em Diefenbach (2011)

A diversidade dos termos que definem o empreendedorismo dentro de organizações pode gerar confusão, bem como contradições. Entretanto, na essência dessa literatura apresentada no Quadro 1, há uma convergência de que as pessoas que trabalham nas organizações podem ser agentes propulsores de inovação em produtos, processos e serviços (PINCHOT, 1985; BURGELMAN; SAYLES, 1986; ZAHRA et al., 1991; HISRICH; PETERS, 2004). Ressalta-se que não há interesse nesta pesquisa de evidenciar as particularidades de cada termo, bem como aprofundar em cada uma das abordagens apresentadas. O intuito foi apresentar um panorama das possibilidades de análise do empreendedorismo nas organizações a partir de diferentes abordagens.

Nesse sentido, outro conceito importante para avaliar o empreendedorismo nas organizações é o de Orientação Empreendedora (OE). Miller (1983) 
destaca que a OE é conceituada através de três perspectivas - a da inovação, da proatividade e da tomada de risco. O referido conceito foi redimensionado por Covin e Slevin (1991) e Lumpkin e Dess (1996). Ao longo dos trabalhos, foram incorporados novos conceitos ao empreendedorismo, porém Rauch et al. (2009) observa que a maioria dos estudos tem adotado as três principais dimensões da OE cunhadas por Miller (1983). Segundo Diefenbach (2011) tanto a orientação empreendedora como o comportamento empreendedor são fatores básicos para a implementação do empreendedorismo na administração pública.

Diante das análises efetuadas, observa-se que às abordagens de empreendedorismo $e$ os conceitos que o caracterizam e o particularizam reforçam $e$ mantém o status quo do empreendedor baseado em seu desempenho. Em outras palavras, o empreendedorismo se afasta do significado original que é fazer da pessoa um sujeito das ações que ele pode executar. Segundo Boava e Macedo (2011) isso se dá pelo motivo do empreendedorismo ter sido ressignificado como um "modo de ver" as coisas e não como um "modo de ser". Na perspectiva dos autores "[...] o modo de ver não informa sobre aquilo que se mostra, mas sim apenas sobre aquilo que se quer enxergar. O modo de ser é uma manifestação do fenômeno que se mostra como ele é, não como parece ser". (BOAVA; MACEDO, 2011, p. 9)

Diante dessas considerações, aponta-se na próxima seção a discussão sobre a incorporação do empreendedorismo no setor público a partir de uma revisão de literatura.

\section{O Empreendedorismo no Setor PÚBLICo (ESP)}

Historicamente, grande parte das teorias organizacional e gerencial foi desenvolvida para organizações em geral, sem distinção entre público e privado. As teorias, Weberiana e Taylorista, são exemplos que defendem implícita ou explicitamente que seus achados se aplicam tanto no setor público quanto no privado, porque organizações públicas e privadas possuem muito mais similaridades do que diferenças (STOKER, 2006; RAINEY, 2009). No entanto, Dienfenbach (2011) argumenta que existem conceitos particulares de cada setor que não podem ser transpostos sem a devida adaptação. (RAINEY, 2009; BERGUE, 2011)

\begin{tabular}{|c|c|c|}
\hline & Empreendedorismo no setor Público & $\begin{array}{c}\text { Empreendedorismo no setor Privado } \\
\text { (Independente) }\end{array}$ \\
\hline Objetivos & $\begin{array}{l}\text { Múltiplose variáveis, de certa forma, mal } \\
\text { definidos. }\end{array}$ & Claros, definidos e consistentes. \\
\hline Autoridade & Maior nível de autoridade e centralização. & Controle mais democrático e descentralizado \\
\hline & Menor autonomia e flexibilidade & Elevado grau de autonomia e flexibilidade \\
\hline $\begin{array}{l}\text { Recompensas/ } \\
\text { Motivação }\end{array}$ & $\begin{array}{l}\text { Baixos incentivos financeiros; sem } \\
\text { redistribuiçãode lucros.Baixocompromisso } \\
\text { e satisfação no trabalho. }\end{array}$ & $\begin{array}{l}\text { Elevados incentivos financeiros; rentabilidade } \\
\text { como principal mecanismo para gerar renda } \\
\text { Elevado nívelde compromissoe satisfaçãono } \\
\text { trabalho. }\end{array}$ \\
\hline Inovação & $\begin{array}{l}\text { Atuam na busca por superar entraves } \\
\text { burocráticos e politicos que muitas vezes } \\
\text { restringem as inovações. }\end{array}$ & $\begin{array}{l}\text { Atuamna criação de valoratravés dainovação } \\
\text { e aproveitamento de oportunidade }\end{array}$ \\
\hline Tomada de risco & $\begin{array}{l}\text { Assume grandes riscos organizacionaissem } \\
\text { tomar grandes riscos pessoais. }\end{array}$ & $\begin{array}{l}\text { Assume siginificativøisco financeiroe pessoal } \\
\text { mas busca minimiza-los. }\end{array}$ \\
\hline Proatividade & $\begin{array}{l}\text { Entende o negócio, bem como se apóia na } \\
\text { oportunidade para crescimento. }\end{array}$ & $\begin{array}{l}\text { Segue uma oportunidade, independentemente } \\
\text { dos recursos que eles controlam. }\end{array}$ \\
\hline $\begin{array}{r}\text { Financiamento } \\
\text { e lucratividade }\end{array}$ & $\begin{array}{l}\text { Não são orientados para o lucro; buscam } \\
\text { obter financiamentospara projetos; maior } \\
\text { disponibilidade de levantar capital. }\end{array}$ & $\begin{array}{l}\text { Orientados pelo lucro; maior dificuldade de } \\
\text { acessar e obter financiamentos. }\end{array}$ \\
\hline
\end{tabular}

Quadro 2: Diferenças entre o Empreendedorismo no setor Público e no setor Privado

Fonte: Adaptado de Kearney et al. (2009, p. 29, tradução nossa)

Segundo Diefenbach (2011), dentre as principais diferenças entre as organizações privadas em relação às públicas, estas se destacam: a) ausência de mercados econômicos e suas pressões de redução de custos; b) influências intensivas de questões políticas; c) pressupostos como a equidade, a responsabilidade, a franqueza e a transparência aos usuários e multiplicidade de conflitos entre os agentes (gestores); e d) tradicionalmente mais centralizada, cujos gestores têm menor autonomia de decisão e flexibilidade, menor incentivo e menores riscos/recompensas (BERNIER; HAFSI, 2007; CURRIE, et al., 2008). Pensar essas características no setor público é um desafio para os atores/agentes que veem na mudança uma possível solução para o desempenho das organizações públicas. Em outras palavras, o contexto do setor público, por ter um alto grau de burocratização inibe uma cultura empreendedora baseada na inovação e também na autonomia e flexibilidade.

A partir da análise Quadro 2 observa-se também que o setor público difere não somente quanto aos fins do setor privado, mas também no processo. Nesse sentido, o desempenho das organizações públicas não guiadas somente pelos valores de gestão, mas também por valores políticos, sociais e institucionais. Assim, no processo de renovação do setor público por meio do empreendedorismo deve se levar em conta os aspectos culturais existentes nas organizações (RAYNEY, 2009), 
a fim de minimizar possíveis dificuldades e desdobramentos não intencionais para a gestão e pessoas envolvidas.

Muitos estudos têm procurado definir o que seria o empreendedorismo no setor público (ROBERTS; KING, 1991; OSBORNE; GAEBLER, 1992; MORRIS; JONES, 1999; KEARNEY, et al.; 2007; RAUCH, et al. 2009). No entanto, as definições existentes sobre esse termo são limitadas e diversificadas. (ROBERTS; KING, 1991; BOYETT, 1997; CURRIE et al., 2008; KEARNEY et al., 2007; 2009; MORRIS; JONES, 1999; MORRIS et al., 2008)

Nesse ínterim, Roberts e King (1991) definem que o Empreendedorismo no Setor Público (ESP) é um processo de introdução de inovação nas organizações presentes neste contexto. Para Roberts (1992), o ESP é a geração de ideia inovadora, a concepção e a implementação dessa ideia no setor público. Osborne e Gaebler (1994) analisam esse termo a partir da compreensão das ações de instituições empreendedoras e de empreendedores públicos. Nesse sentido, explicam que eles usam recursos disponíveis e constroem novas maneiras para maximização da produtividade e efetividade organizacional.

Morris e Jones (1999) tratam esse conceito pela perspectiva do processo de criação de valor para os cidadãos, ao reunir uma combinação de recursos públicos para explorar oportunidades sociais. Dessa forma, o ESP implica em um papel inovador e proativo do governo na condução da sociedade para melhoria da qualidade de vida, com a inclusão de geração de receitas alternativas, melhoria de processos internos e desenvolvimento de soluções inovadoras para satisfazer as necessidades sociais e econômicas. (DIEFENBACH, 2011)

Para Shockley et al. (2006), o ESP ocorre sempre que um ator político está em alerta com as problemáticas da administração pública e age em oportunidades potenciais de lucro, mudando o sistema em que ator está incorporado em direção ao equilíbrio. Kearney et al. (2007) refere-se à empresa estatal/serviço civil. Sob esse aspecto, o ESP é definido como um indivíduo ou grupo de indivíduos que se compromete com a atividade desejada para iniciar a mudança dentro da organização, na qual busca adaptar, inovar e facilitar o risco. Nessa conceituação, metas e objetivos pessoais são menos importantes do que a geração de um bom resultado para a organização pública.
Na conceituação de Currie et al. (2008), o ESP é visto como o processo de identificação e busca de oportunidades de indivíduos e, ou, organizações. Além disso, esse processo é muitas vezes caracterizado pela capacidade de inovação, tomada de riscos e proatividade. Morris et al. (2008) evidenciam que as organizações podem ser caracterizadas em termos de sua orientação ou intensidade empreendedora, que é um reflexo das atividades empresariais no qual estão fazendo. Essas atividades são baseadas no conceito de Orientação Empreendedora (inovadoras, arriscadas e proativas). Os passos básicos para esse processo identificado (no setor privado) não deve ser diferente em um contexto de organizações públicas.

Alguns autores também se dedicaram a definir o perfil do empreendedor público. Nesse sentido, Ramamurti (1986) afirma que o empreendedor público é um indivíduo que se compromete para iniciar e manter uma ou mais organização do setor público. Para Bellone e Goerl (1992), o empreendedor público pode ser definido a partir de quatro características, a saber: 1) autonomia; 2) visão pessoal do futuro; 3) sigilo; e 4) tomada de risco. Essas características, segundo este autor, podem ser conciliadas com os valores democráticos fundamentais como accountability, participação cidadã, formulação de políticas públicas transparentes e planejamento de longo prazo. Já Roberts (1992) caracteriza o empreendedor público como um indivíduo que gera, projeta e implementa ideias inovadoras no domínio público.

Na visão de Schneider et al. (1995), o empreendedor público é definido por dois fatores: 1) sua vontade de tomar medidas de risco; e 2) sua capacidade de coordenar as ações de outras pessoas para cumprir metas. Segundo Currie et al. (2008), o empreendedor público é um líder que amplia metas, mandatos, funções e poder de suas organizações de forma não prevista pelos agentes públicos. Ele constrói coalizões políticas para usufruir as oportunidades na organização.

Apesar de difusas, as definições de empreendedorismo no setor público também se aproximam em alguns aspectos (DIEFENBACH, 2011). Um dos aspectos são as dimensões inovação, proatividade e tomada de riscos. Elas se repetem em várias conceituações, como a conceituação de Kearney (2007), Currie et al. (2008) e Morris et al. (2008). Outro ponto em comum é que algumas conceituações incorporam o conceito 
de criação de valor, o qual é evidenciado por Morris e Jones (1999) e Bernier e Hafsi (2007).

Observa-se que o conceito empreendedorismo público, portanto, ainda está em formação e que as suas influências estão arraigadas em pesquisas internacionais, principalmente europeias, que têm se dedicado a compreender melhor esse conceito. (MORRIS; JONES, 1999; SADLER, 2000; BARNIER; HAFSI, 2007; MORRIS et al., 2008; CURRIE, et al. 2008; KEARNEY et al., 2009; DIEFENBACH, 2011)

A partir da análise das diferenças mencionadas no Quadro 2, observa-se que a transposição de práticas de um setor para outro se torna delicada (BERGUE, 2011), pois, cada setor apresenta características peculiares que torna a incorporação de conceitos complexa. Portanto, é preciso conceber o empreendedorismo público como um conceito em processo de formação. Muito se tem a elucidar de sua verdadeira contribuição para a administração pública, dado que a discussão sobre empreendedores no setor público é balizada, principalmente, em um modelo de administração pública gerencial, passível de inúmeras críticas.

No Brasil, nos últimos anos, tem surgido a noção de empreendedorismo público. Identificou-se de forma exploratória que um governo estadual de uma unidade federativa no país possui indicativos de empreendedorismo público, os quais podem ser verificados pela criação e pelo gerenciamento de um cargo, comissionado e de livre nomeação, cuja denominação faz alusão a essa noção (VALADARES; EMMENDOERFER, 2012; VALADARES; EMMENDOERFER; SILVA, 2013; EMMENDOERFER; VALADARES, 2014). Impulsionado por essa evidência, buscou-se compreender a aplicabilidade do empreendedorismo no setor público brasileiro. No entanto, antes de fazer as devidas análises, é necessário contextualizar a realidade da administração pública brasileira. Dessa forma, na próxima seção, buscar-se-á caracterizar, de forma sucinta, a evolução da administração pública nesse país.

\section{Breve Histórico da Evolução da Administração Pública Brasileira}

Na tentativa de modernizar a administração do Estado brasileiro, os governos, ao longo da história, buscaram, por meio de reformas administrativas, me- lhorar o desempenho do setor público (SECCHI, 2009; LUSTOSA DA COSTA, 2010; VALADARES et al., 2013). Essas reformas se materializaram em modelos que, com suas características próprias, contribuíram, e ainda contribuem, para formação da modernização do Estado brasileiro. É possível observar a presença de pelo menos quatro modelos de administração pública relevantes no contexto brasileiro: a) Patrimonial (FAORO, 2000; NUNES, 2010); b) Burocrático (WEBER, 1999); c) Gerencial (HOOD, 1991; POLLITT, 2000); d) Gestão Social (TENÓRIO, 1998) também chamado de Societal (PAES DE PAULA, 2005) e pode também ser visto como Novo Serviço Público. (DENHARDT, 2012)

Apesar da existência desses quatro modelos teóricos, observa-se que na história de administração pública brasileira, não é possível enquadrá-la em um só modelo (TORRES, 2004), pois ela é caracterizada por uma gestão híbrida, na qual os três modelos (patrimonial, burocrático e gerencial) coexistem na estrutura administrativa (ZWICK et al., 2012). No entanto, observa-se que apesar da irregularidade, um modelo sempre se sobrepôs ao outro em relação ao período que estava em evidência. É possível afirmar que o modelo patrimonialista é encontrado em todas as fases da modernização do Estado supracitado, o que faz dele uma característica dominante na administração pública brasileira. (JANOTTI, 1987; NUNES, 2010; FAORO, 2000; HOLANDA, 2000; PAES DE PAULA, 2005; MATIAS-PEREIRA, 2009; CABOBIANGO et al., 2010)

Historicamente, até a Revolução de 1930, o Estado brasileiro era refém dos interesses de uma elite agrária composta de aristocráticos proprietários rurais. Desde os tempos de colônia, é possível observar que o Estado brasileiro absorveu práticas da metrópole portuguesa em sua forma de administrar. Outro traço importante da cultura brasileira era o personalismo. Uma das expressões clássicas que evidenciam o personalismo é "Você sabe com quem está falando?".

Segundo Roberto da Matta em Carnavais, malandros e heróis, uma das características peculiares do sistema cultural brasileiro seria o personalismo entendido como uma caracterização do sistema hierárquico social que se baseia em distinguir os indivíduos das pessoas (LUSTOSA DA COSTA, 2010). Matta (1980, p. 14) observa que o Brasil do seria caracterizado pelos "[...] carnavais e hierarquias, igualdades e aristocracias, com a cordialidade do encontro cheio de sorrisos cedendo 
lugar no momento seguinte, à terrível violência dos antipáticos "você sabe com quem está falando?"”.

A obra mais conhecida sobre o patrimonialismo no Brasil é creditada a Raymundo Faoro intitulada Os donos do poder publicado em seu volume original no ano de 1957. Nessa obra, Faoro (2000) utiliza das formas de dominação definidas por Weber (1999), a saber: a) carismática; tradicional e racional-legal. Observa-se que "[...] o conceito de patrimonialismo aparece, na sociologia weberiana, no contexto da dominação tradicional, ora como sinônimo desta, ora como um tipo específico, ao lado do feudalismo". (LUSTOSA DA COSTA, 2010, p. 31)

Ao estabelecer o patrimonialismo nas bases da dominação tradicional de Weber (1999), Faoro (2000) mostra que a administração patrimonial é voltada para os interesses particulares de uma classe dominante, no qual as relações públicas se dão por meio da tradição. Nessas relações predominam: a) a indistinção entre bem público e privado; b) concentração de poder no governante (soberano); c) administração pública voltada para grupos dominantes; d) personalismo; e) não profissionalização da administração pública; f) tendência à corrupção (FAORO, 2000; CAMPANTE, 2003). A partir da percepção de que para alcançar eficiência administrativa no Estado era preciso deixar de lado a administração patrimonial propôs-se no Brasil, ainda oligárquico, um modelo baseado nos moldes da burocracia tratadas por Max Weber.

A urbanização e industrialização que o Brasil experimentou a partir de 1930 fizeram com que o país passasse por um rearranjo político do Estado, atendendo às pressões para modernização deste por parte da burguesia (TORRES, 2004; LUSTOSA DA COSTA, 2008; NUNES, 2010). Em 1935 foi proposta uma reforma da administração pública com o objetivo de superar as deficiências do modelo patrimonial e para uma profissionalização da administração pública brasileira. Criou-se então o Departamento Administrativo do Serviço Público (DASP) visando à promoção de uma máquina administrativa baseada nas reformas burocráticas do serviço público realizadas em países desenvolvidos. Destaca-se que, neste período, o país estava passando por um processo histórico importante que remetia as revoluções de 1930, no qual o poder do Estado brasileiro passava das mãos das elites agrárias para as mãos de Getúlio Vargas. No mundo, a situação também era de mudanças, pois, com a crise de 1929 , os Estados estavam em busca de uma nova forma de administrar a máquina pública. (TORRES, 2004; LUSTOSA DA COSTA, 2008)

Com a criação do DASP fica evidente a busca por profissionalização da administração pública e a tentativa de romper com o modelo patrimonial até então vigente. A reforma administrativa de 1935 pode ser considerada como um esforço inicial para a burocratização da administração pública brasileira. Ainda relacionado aos processos de mudanças na administração pública brasileira, em 1967, no contexto do Estado nacional desenvolvimentista, foi proposto o Decreto-Lei 200 que se tornou o marco da reforma gerencial implementada pelos militares. Segundo Lustosa da Costa (2008, p. 850) são cinco os princípios que caracterizam esse decreto: a) planejamento; b) "[...] expansão das empresas estatais bem como de órgãos independentes (fundações públicas) e semi-independentes (autarquias)"; c) fortalecimento do sistema meritocrático; d) "[...] diretrizes para um novo plano de classificação de cargos [...]"; e) criação de vários ministérios.

Deve-se ressaltar que a reforma administrativa de Vargas foi um dos primeiros esforços para superação do modelo patrimonial em voga no contexto brasileiro, embora suas raízes patrimoniais não tenham sido suplantadas. Essas ligações, segundo Holanda (2000), são características fundamentais do "homem cordial" brasileiro que, em sua caminhada e busca pelo poder, não consegue distinguir os aspectos público e privado.

Prosseguindo na reforma administrativa burocrática, no contexto do governo militar da década de 1960, surgiu um decreto-lei que visava modernizar a administração pública por meio da utilização de instrumentos gerenciais utilizados pela iniciativa privada (NUNES, 2010; VALADARES et al., 2013). Além da normatização e da padronização de procedimentos nas áreas de pessoal, compras governamentais e execução orçamentária, buscava-se também estruturar o governo. As estratégias adotadas para alcançar a estruturação seriam planejamento, coordenação, descentralização, delegação de competências, controle e investimento em administração indireta. (LUSTOSA DA COSTA, 2008)

$\mathrm{Na}$ tentativa de evoluir os quadros existentes frente às limitações dos modelos preconizados e ins- 
titucionalizados na administração pública brasileira, foi instituída uma nova reforma, que aconteceu em 1995, dando início ao modelo gerencial (BRESSER-PEREIRA, 2003). O modelo gerencial foi estabelecido em 1995, no governo de Fernando Henrique Cardoso com a denominada reforma Bresser. Deve-se destacar que com essa reforma, o Brasil estava aderindo às diretrizes apresentadas pelos governos baseados no modelo gerencialista de administração pública. O marco desta reforma foi o Plano Diretor da Reforma do Aparelho do Estado (PDRAE) em 1995. Segundo Lustosa da Costa (2008, p. 863), o plano tinha como objetivo instaurar a administração gerencial no Brasil a partir do ajustamento fiscal, das "[...] reformas econômicas orientadas para o mercado que, acompanhadas de uma política industrial, garantissem a concorrência interna e criassem condições para o enfrentamento da competição internacional [...]", da reforma da previdência social, de inovar na questão dos instrumentos das políticas sociais produzindo uma boa qualidade dos mesmos e da "[...] reforma do aparelho do Estado, com vistas a aumentar sua 'governança', ou seja, sua capacidade de implementar de forma eficiente políticas públicas". (LUSTOSA DA COSTA, 2008, p. 863)

Com essa reforma, o governo brasileiro visava substituir o modelo burocrático, "[...] misturado a práticas clientelistas ou patrimonialistas, por uma administração pública gerencial, que adota os princípios da nova gestão pública" (BRESSER-PEREIRA, 1999, p. 6). Nesse trecho é possível observar que os reformistas de 1995 criticavam as reformas anteriores (1935 e 1967) por não conseguirem suplantar totalmente o patrimonialismo da administração pública brasileira. O objetivo da reforma gerencial seria afastar o Estado de práticas patrimonialistas por meio de uma gestão baseada em resultados. Para tanto, foi dado ênfase ao federalismo em que se pressupunha, segundo Bresser-Pereira (1998): a descentralização das políticas sociais para os estados e municípios, sendo delimitada a atuação do Estado; a separação entre formulação e execução de políticas públicas; a maior autonomia para as atividades exclusivas do Estado, ou seja, da União; e ainda buscou-se a garantia da responsabilização (accountability) dos agentes públicos pela administração por objetivos.

A reforma gerencial de 1995 trouxe mudanças de conceitos em toda estrutura pública administrativa do país, pois se objetivou um Estado mais gerencial, a partir do distanciamento de práticas patrimoniais e burocráticas (BRESSER-PEREIRA, 2010). O Estado passaria a priorizar os resultados de sua administração e não as questões jurídico-legais. Segundo esse autor, a reforma gerencial foi um dos produtos da grande evolução da forma que o Brasil estava propondo. A modernização da Administração Pública foi pautada em contratações de técnicos competentes, extinção de secretarias e cargos públicos, fixação de tetos salariais do poder executivo e atualização de processos de compras e licitações (BRESSER-PEREIRA, 2010). Portanto, passa-se a aplicar como foco central na gestão do Estado brasileiro, a partir da reforma gerencial de 1995, a administração por resultados.

Depois de ser institucionalizado o modelo gerencial, surgiram várias críticas a esse modelo, principalmente no que diz respeito à falta de participação social em relação à tomada de decisão dos governos. Nesse ínterim, Paes de Paula (2005) destaca que a literatura especializada permite encontrar as seguintes limitações no modelo de administração pública gerencial: a) formação de uma nova elite burocrática e centralização do poder nas instâncias executivas (HOOD, 1991; FREDERICKSON, 1996); b) inadequação da utilização das técnicas e práticas, advindas do setor privado, no setor público; c) dificuldade em lidar com a complexidade dos sistemas administrativos e a dimensão sociopolítica da gestão (SCOTT, 1996); d) incompatibilidade entre a lógica gerencialista e o interesse público (HOOD, 1991). Além disso, de acordo com Zwick et al. (2012, p. 285), no caso brasileiro observa-se que:

[...] a importação do modelo da nova adminis-
tração pública (NAP) carrega peculiaridades
típicas das empresas privadas, sendo utilizado
sem que se tenha empreendido uma leitura crí-
tica sobre esse processo de implementação por
parte dos proponentes. Isso pode ser explicado,
em parte, pelo fato de o Brasil ter sido um país
colonizado, no qual se formou uma cultura de
aceitação passiva do estrangeiro.

Isso coaduna com Misoczky (2006) ao sugerir que o gerencialismo pode ser ter ganhado tal popularidade pelo fato de seus formuladores terem se fascinado pelos padrões advindos de países considerados desenvolvidos. Nessa perspectiva, o Brasil por ter herdado traços de seu processo de colonização (MATTA, 1980). 
O fascínio pelo novo e uma produção e reflexão domesticada, tornando-se também, como em vários outros países pelo mundo afora (KETTL, 2006), dominado pela ideologia neoliberal, que amparado pela doutrina do choque (KLEIN, 2008) tornou-se hegemônica em termos de administração pública.

Diante desse contexto e do esgotamento das teorias tradicionais advindas do contexto anglo-saxão que reforçam os preceitos apregoados pelo taylorismo-fordismo (CANÇADO; TENÓRIO; PEREIRA, 2011) surge à gestão social como uma alternativa para o desenvolvimento de uma administração pública mais emancipatória (TENÓRIO, 2008). Isso implica realizar reflexões para além da gestão clássica de políticas públicas, visando:

[...] estabelecer as articulações entre ações de intervenção e de transformação do campo social, que é uma noção mais ampla, e que não se restringe à esfera público-governamental, como vemos a exemplos das ações de responsabilidade social e do crescimento do terceiro setor. (GOMES et al., 2008, p. 59)

Assim, a gestão social é desenvolvida sob a perspectiva de emancipação dos grupos sociais organizados. Sua concepção está arraigada na democracia deliberativa (HABERMAS, 2003) e na ação comunicativa de Habermas (1987) que tem como pressupostos uma consciência crítica e uma crítica à razão instrumental. O campo da gestão social desta forma se delimita de forma dialógica dando oportunidades para o surgimento de práticas "diferenciadas e inovadoras". (CANÇADO; TENÓRIO; PEREIRA, 2011, p. 695)

Deve-se destacar que a gestão social também pode ser vista como Modelo Societal de Administração Pública (PAES DE PAULA, 2005) e como Novo Serviço Público (DENHARDT, 2012). No entanto, é possível observar que os três conceitos se assemelham, principalmente no que tange à retomada social (pela razão crítica, emancipação, práxis) do poder e do interesse público, no qual o bem público ou o serviço público é realizado com a sociedade e pela sociedade (PAES DE PAULA, 2005; CAPOBIANGO, et al., 2010). Essa perspectiva denota uma administração pública voltada para o cidadão. Entretanto, ressalta-se que esse modelo ainda está em processo de construção, de modo que ainda seja um campo fértil de pesquisas para sua consolidação. (CANÇADO; TENÓRIO; PEREIRA, 2011)

\section{Reflexões Acerca da Incorporação DO EMPREENDEDORISMO NA Administração Pública Brasileira}

Nas seções anteriores, observou-se que pouco tem sido escrito sobre a incorporação do empreendedorismo na administração pública (SADLER, 2000; KEARNEY, 2009; DIEFENBACH, 2011; EMMENDOERFER; VALADARES, 2014). No que tange à produção nacional, observou-se por meio de uma busca exploratória nos principais periódicos indexados na área de administração na CAPES que a produção é também muito incipiente e ainda concentrada em alguns periódicos como a Revista de Administração Pública, o Cadernos EBAPE.BR, Revista de Administração Contemporânea, Revista de Ciências de Administração, dentre outras. Além disso, o que existe nesta literatura baseia-se, em grande parte, no pensamento abstrato, decorrente da apropriação de estudos do empreendedorismo no setor privado (SADLER, 2000). O que é justificado, principalmente porque o termo empreendedorismo tem sido estudado via o discurso da nova administração pública. (SECCHI, 2009; VALADARES; EMMENDOERFER, 2012)

O discurso da nova administração pública é criticado principalmente devido ao fato de trazer a cultura do management para a administração pública sem o devido rigor com relação às particulares locais. De acordo com Faria (2005, p. 5)

[...] a falta de rigor pode ser comparada a uma cesta em que tudo cabe, não importando o quanto incompatíveis são os ingredientes. Neste caso, conceitos retirados de várias teorias com origens epistemológicas diversas são utilizados sem critérios, bastando que possam dar uma explicação razoável aos dados da realidade que o pesquisador encontrou.

Nesse ínterim, segundo Vogel (2012), a legitimidade e a superioridade do modelo gerencial são produtos do discurso.

Como prova disso, basta analisar a obra Reinventando o Governo, de Osborne e Gaebler (1994), 
que se torna central para a difusão $e$ a aplicação da noção de empreendedorismo no setor público, e observar suas intensas aproximações com a New Public Management. Sobre essa obra, Raadschelders (2012) verificou que é possível encontrar contradições em relação à aplicação dessa noção, apesar de ela ter se tornada popular tanto pela importância do arcabouço teórico contextualizado ao setor público, quanto pela abordagem neoliberal. Vale lembrar que essa abordagem tem influenciado a gestão pública mundial, ao enfatizar o uso de instrumentos de gestão empresarial e de uma racionalização instrumentalizada para os gestores públicos (ANDREWS; KOUZMIN, 1998; KETTL, 2006; KLEIN, 2008; SECCHI, 2009; DIEFENBACH, 2011). Especificamente, segundo Paes de Paula (2005, p. 61), as ideias de Osborne e Gaebler (1994) "[...] comprova que o gerencialismo havia se deslocado do setor privado para o setor público".

Sobre o impacto da incorporação do empreendedorismo via New Public Management como apregoado por Osborne e Gaebler (1994), Raadschelders (2012, p.897, grifo nosso) sugere que isso é questionável por que:

Surely, it had impact, especially when the Clinton-Gore administration jumped on it as the inspiration for their National Performance Review, with Gore erroneously claiming that business management had served as an example to public management "throughout the ages" (GORE, 1993, p. 8). But, was Gore influenced by it in a lasting way? In addition, how original were Osborne and Gaebler? As much as they tried to suggest that their entrepreneurial focus was different from that during the Progressive Era and the New Deal, much of their argument has its roots exactly in those two periods (Green \& Hubbell, 1996). I suggest that Osborne and Gaebler gained popularity, because they rode on an emerging wave of renewed attention for managerial principles (new public management).

Com base nas críticas já levantadas, observa-se que da mesma forma como a nova administração pública foi construída via pensamento ideológico neoliberal o pensamento neoliberal tem sido base norteadora para a criação de práticas empreendedoras na gestão pública. Sendo assim cabe refletir se a incorporação do empreendedorismo na gestão públi- ca via pensamento reformista pode trazer benefícios sociais e sustentáveis para ela e, principalmente, para a sociedade. (ANDREWS; KOUZMIN, 1998; COSTA; BARROS; CARVALHO, 2011)

Ao analisar os períodos históricos da gestão pública brasileira, observa-se que apesar de apresentar uma evolução, ela é caracterizada pelo hibridismo. No entanto, ao analisar o atual momento da gestão pública, inclusive das formas como as políticas públicas são conduzidas, é perceptível que o modelo gerencial está em voga apesar de uma busca por um modelo mais substantivo como o da gestão social. (ZWICK et al., 2012)

Ao predominar uma lógica gerencialista, no qual os princípios da administração pública seguem uma lógica instrumental, essa mesma administração pública se torna suscetível a influências dominantes e colonizadoras que fortalecem a elite no poder. O que é observado em Secchi (2009) ao constatar que a incorporação do termo Empreendedorismo no Setor Público (ESP), no âmbito do modelo gerencial, pode ser pelo fato de essa prática se tornar um instrumento de retórica para políticos. Em outras palavras, ao utilizar das conotações provenientes de uma gestão empreendedora, determinado governante ou partido político poderá utilizar esse discurso como instrumento de novidade, projetando a imagem do governante e dos atores políticos interessados no seu governo. Dessa forma, observa-se que a adoção de empreendedorismo no setor público brasileiro pode estar atrelada ao discurso de governantes para que possam alcançar legitimação e manutenção de poder (VALADARES; EMMENDOERFER, 2012), assim como o discurso da nova administração pública o foi. (ANDREWS; KOUZMIN, 1998)

Assim, a incorporação do ESP não pode estar desatrelada do pensamento reflexivo e de uma práxis libertadora e emancipatória presentes no campo. Nesse ponto reside a importante contribuição de Alberto Guerreiro Ramos (1965) para as pessoas que queiram analisar o ESP. Para esse autor, inspirado na construção da redução fenomenológica de Edmund Husserl e Martin Heidegger, o processo de transposição deveria ocorrer de maneira reflexiva resguardando o caráter essencial do elemento transportado. Isso é essencial nos tempos atuais, pois conforme Faria (2012, p. 5) um dos grandes problemas das pesquisas em Administração 
tem sido "[...] recorrer a conceitos oriundos de determinada Dimensão Epistemológica trazendo junto com eles os pressupostos epistêmicos desta Dimensão não compatíveis com os da Dimensão em que o sujeito da pesquisa está trabalhando" (FARIA, 2012, p. 5). E mais, "[...] disto tem resultado diversos trabalhos acadêmicos confusos, epistemologicamente incoerentes e inconsistentes, com graves repercussões tanto metodológicas quanto teóricas". (FARIA, 2012, p. 5)

Nesse âmbito, o processo de redução sociológica, segundo Ramos (1965), seria regido por quatro leis importantes: a) a Lei do comprometimento, que é orientada pelo compromisso com a organização, posiciona-se de forma crítica e reflexiva em relação aos pressupostos do conteúdo estrangeiro e opõe-se à fixação pelo estrangeiro e assunção direta de conteúdo exógeno; b) a Lei do caráter subsidiário da produção científica estrangeira, que propõe a permeabilidade da organização a inovações gerenciais, a subsidiariedade do conteúdo estrangeiro, valoriza os pressupostos que configuram o contexto de origem e tem como compromisso produzir conhecimento endógeno; c) a Lei da universalidade dos enunciados gerais da ciência, que tem como ideal central os conceitos referenciados à organização e ao setor, apresenta uma atitude subordinada; d) a Lei das fases, que se conscientiza das fases experimentadas pelos contextos de origem e destino, assume que tudo que acontece em determinado momento em uma sociedade adquire o seu exato sentido, assume que a razão dos problemas de uma sociedade é dada pela fase em que esta se encontra.

Sendo assim, o conceito de redução sociológica é relevante no contexto da transposição de conceitos e técnicas gerenciais para o setor público porque contribui na qualidade de procedimento crítico-assimilativo. Isso é possível por meio de seus critérios rígidos e com base no processo reflexivo, faz com que as pessoas nas organizações prezem o conteúdo do conceito ou tecnologia gerencial em detrimento de seu formato, evitando assim práticas cerimoniais. Isto se torna crucial no processo de transposição do conceito de empreendedorismo para o setor público, pois, através de uma assimilação crítica de conteúdos do setor privado, os atores públicos poderão solucionar problemas como a adaptação dessas tecnologias gerenciais no setor público e as evidências de que tal processo opera predominantemente no nível superficial desses objetos culturais (PAES DE PAULA, 2005) da mesma forma que ocorrem nas organizações privadas. (SERVA, 1997; ABRAHAMSON, 1996; CALDAS; WOOD JÚNIOR, 1999)

\section{Considerações Finais}

Este ensaio sugere que o desenvolvimento de empreendedores no setor público possui conotação dupla. De um lado, com sua visão de futuro, autonomia e tomada de risco contribui para construir novas maneiras para maximizar a produtividade e a efetividade organizacionais (DIEFENBACH, 2011). Por outro lado, representa riscos para a manutenção da democracia no setor público, no qual suas ações podem visar a interesses próprios. (SADLER, 2000)

Segundo a literatura, três grandes temas limitam a aplicabilidade dessa noção no setor público: 1) a ameaça à governabilidade democrática, em que a principal crítica reside na falta de legitimidade (DELEON; DENHARDT, 2000); 2) esses empreendedores podem perseguir interesses próprios, fazerem mal uso de fundos públicos, estabelecerem domínio sobre outros (poder), implementarem mudanças radicais, ignorando, assim, padrões das organizações públicas (CURRIE et al., 2008); e 3) os objetivos da atividade empresarial não está completamente alinhada aos objetivos da organização pública, o que pode gerar, por conseguinte, a mudança de foco do gestor público, ou seja, ele pode negligenciar as suas principais responsabilidades que está centrada no usuário. (MORRIS; JONES, 1999)

Com as reflexões levantadas neste artigo, compreende-se que o empreendedorismo se torna um desafio no contexto do setor público, pois, esse setor não se compatibiliza com a lógica empresarial. No entanto, não se pode ignorar que elementos substantivos do empreendedorismo podem contribuir para o melhor desempenho do setor público brasileiro. O problema maior de se promover esta noção no setor público refere-se a quem a promove, pois, na maioria das vezes, estes indivíduos estão dispostos a alcançar resultados pessoais em detrimento dos resultados públicos. No discurso destes, está presente o compromisso com as demandas da sociedade, porém, em muitas vezes, observa-se que o compromisso destes é com eles mesmos. Com isso, há a busca de legitimar-se a longo 
prazo, manter relações políticas favoráveis e garantir cargos eletivos. Nesse sentido, passam-se as eleições e também, possivelmente, os compromissos públicos.

O empreendedorismo, portanto, sob a lógica da racionalidade instrumental aplicada às organizações públicas, pode representar um grande risco para a administração pública brasileira, pois manterá os mesmos resultados gerados pelo gerencialismo (a saber: valorização dos instrumentos de gestão e do pensamento ideológico neoliberal). Dessa forma, a despeito de suas contribuições, a implementação do empreendedorismo em organizações públicas não se alinha aos ideais emancipatórios e segue à lógica do desempenho, que norteia o modelo da Nova Administração Pública. Nesse sentido, conforme destaca Sadler (2000), o empreendedor pode se tornar um risco para a administração pública, pois pode adotar várias facetas em busca de seu objetivo próprio, podendo ser caracterizado como um camaleão dentro do setor público, que muda de cor em razão do atendimento de seus objetivos particulares.

\section{Agradecimentos}

Resultado de pesquisa com bolsas de doutorado e de estágio pós-doutoral (Processo BEX-1254/14-6) com fomento da Coordenação de Aperfeiçoamento de Pessoal de Nível Superior (CAPES).

\section{REFERÊNCIAS}

ABRAHAMSON, E. Management Fashion. Academy of Management Review, EUA. v. 21, n. 1, p. 254-285, 1996.

ANDREWS, C. W.; KOUZMIN, A. O discurso da Nova Administração Pública. Luz Nova, São Paulo, n. 45, p. 97-129, 1998.

ANTONCIC, B.; HISRICH, R. D. Intrapreneurship: construct refinement and crosscultural validation. Journal of

Business Venturing, New York, v. 16, p. 495-527, 2001.

BAUMOL, W. J. Entrepreneurship in Economic Theory.

The American Economic Review, EUA. v. 58, p. 64-71, 1968.
BELLONE, C. J.; GOERL, G. F. Reconciling public entrepreneurship and democracy. Public Administration Review, EUA. v. 52, n. 2, p. 130-134, 1992.

BERGUE, S. T. A Redução Gerencial no Processo de Transposição de Tecnologias de Gestão para Organizações Públicas. In: ENCONTRO NACIONAL DA ASSOCIAÇÃO DE PÓS-GRADUAÇÃO E PESQUISA EM ADMNISTRAÇÃO, 32. Anais... Rio de Janeiro: ANPAD, 2008. CD.

Modelos de gestão em organizações públicas: teorias e tecnologias gerenciais para análise e transformação organizacional. Caxias do Sul, RS: Educs, 2011.

BERNIER, L.; HAFSI, T. The changing nature of public entrepreneurship. Public Administration Review, EUA. v. 67 , n. 3, p. 488-503, 2007.

BOAVA, D. T.; MACEDO, F. M. F. Empreendedorismo à maneira dos filósofos. In: ENCONTRO DE ESTUDOS EM ESTRATÉGIA, 5, Anais... Porto Alegre: ANPAD, 2011. CD.

BOYETT, I. The public sector entrepreneur - a definition. International Journal of Entrepreneurial Behaviour and Research, EUA. v. 3, n. 2, p. 77-92, 1997.

BRESSER-PEREIRA, L. C. Reforma do Estado para a cidadania: a reforma gerencial brasileira na perspectiva internacional. Brasília, DF: Enap/Editora 34, 1998.

BRESSER-PEREIRA, L. C. Reflexões sobre a reforma gerencial brasileira de 1995. Revista do Serviço

Público, Brasília, DF, v. 50, n. 4, p. 5-30, 1999.

BURGELMANN, R. A. Designs for Corporate Entrepreneurship. Californian Management Review, California, v. 26, p. 154-66, 1983.

BURGELMAN, R. A.; SAYLES, L. R. Inside corporate innovation strategy, structure and managerial skills. New York: The freepress, 1986.

BYGRAVE, W. D. Theory building in the entrepreneurship paradigm. Journal of Business Venturing, EUA. v. 8, n. 3, p. 255-280, 1993.

CALDAS, M. P.; WOOD JÚNIOR, T. Para inglês ver: importando tecnologia gerencial no Brasil. In: CALDAS, M. P.; WOOD JÚNIOR, T. Transformação e realidade organizacional: uma perspectiva brasileira. São Paulo: Atlas, 1999. 
CANÇADO, A. C.; TENÓRIO, F. G.; PEREIRA, J. R. Gestão social: reflexões teóricas e conceituais. Cadenos EBAPE.BR, Rio de Janeiro, v. 9, n. 3, 2011.

CAPOBIANGO, R. P.; NASCIMENTO, A. de L. do; FARONI, W.; SILVA, E. A. Reformas Administrativas no Brasil: Uma Abordagem Teórica e Crítica. In: ENCONTRO DE ADMINISTRAÇÃO PÚBLICA E GOVERNANÇA, 4. Vitória, 2010. Anais... Vitória: ANPAD, 2010. CD-ROM.

CAMPANTE, R. G. O patrimonialismo em Faoro e Weber e a sociologia brasileira. Dados - Revistas de Ciências Sociais, Rio de Janeiro, v. 46, n. 1, p. 153-193, 2003.

CARUANA, A.; EWING, M.T.; RAMASESHAN,

Ram. Effects of some environmental challenges and centralization on the entrepreneurial orientation and performance of public sector entities. Services Industries Journal, EUA. v. 22, n. 2, p. 43-58, 2002.

COOKE, B. The managing of the (Third) World.

Organization, Inglaterra, v. 11, n. 5, p. 603-29, 2004.

CORNWALL, J. R.; PERLMAN, B. Organisational

Entrepreneurship. Irwin: Homewood, 1990.

COSTA, A. M. da; BARROS, D. F.; CARVALHO, J. L. F.

A dimensão histórica dos discursos acerca do empreendedor e do empreendedorismo. Revista de

Administração Contemporânea, Curitiba, v. 15, n. 2, 2011.

COVIN, J. G.; SLEVIN, D. P. A conceptual model of entrepreneurship as firm behavior. Entrepreneurship

Theory and Practice, EUA. v. 16, n. 1, p. 7-25, 1991.

CURRIE, G.; et al. Entrepreneurial leadership in the English public sector: Paradox or possibility? Public

Administration, EUA. v. 86, n. 4, p. 987-1.008, 2008.

CUNNINGHAM, J. B.; LISCHERON, J. C. Defining

Entrepreneurship. Journal of Small Business

Management, EUA. v. 29, n. 1, p. 45-67, 1991.

DELEON, L.; DENHARDT, R. B. The political theory of reinvention. Public Administration Review, EUA. v. 60, n. 2, p. 89-97, 2000.

DENHARDT, R. Teoria geral de organizações públicas.

4. ed. São Paulo: Cengage Learning, 2012.
DIEFENBACH, F. E. Entrepreneurship in the public sector: when middle managers create public value. Gabler Research, Gabler Verlag Wiesbaden, 2011.

DRUCKER, P. F. Innovation and entrepreneurship: practice and principles. Londres: Butterworth-Heinemann, 1985.

EMMENDOERFER, M. L.; VALADARES, J. L. Reflexões e Perspectivas acerca da Construção do Conhecimento sobre Empreendedorismo Interno. Revista de Ciências de Administração, Florianópolis, v. 13, n. 30, maio-ago. 2011.

EMMENDOERFER, M.; VALADARES, J. L. Analysis of the public entrepreneurship phenomenon in a Brazilian state. Tourism \& Management Studies, Portugal. v. 10, edição especial, p. 43-48, 2014. Disponível em: <http:// tmstudies.net/index.php/ectms/article/view/636/1072>. Acesso em: 21 fev. 2014.

FAORO, R. Os donos do poder: formação do patronato político brasileiro. 10. ed. São Paulo: Globo, 2000. (v. 2)

FARIA, J. H. Dimensões da Matriz Epistemológica em Estudos em Administração: uma proposição. In: ENCONTRO NACIONAL DA ASSOCIAÇÃO DE PÓSGRADUAÇÃO E PESQUISA EM ADMNISTRAÇÃO, 36.

Anais... Rio de Janeiro: ANPAD, 2012. CD-ROM.

FILION, L. J. From entrepreneurship to entrepronology. In: ICSB World Conference, 42, San Francisco: ICSB, 1997.

FREDERICKSON, H.G. Comparing the reinventing government movement with new public administration.

Public Administration Review, EUA. v. 56, n. 3, p. 263270, 1996.

GOMES, G. da S. et al. Residência Social \& EaD: alternativas multireferenciais nos estágios de graduação na UNITINS. In: CANÇADO, A. C. et al. (Org.). Os desafios da formação em gestão social. Palmas, TO: Provisão, 2008.

HABERMAS, J. Teoría de la accióm comunicativa II: crítica de la razón funcionalista. Tradución de Manuel Jiménez Redondo. Madrid: Taurus, 1987.

Direito e democracia: entre facticidade $e$ validade. 2. ed. Rio de Janeiro: Tempo Brasileiro, 2003. (v. 2) 
HASHIMOTO. M. Organizações intra-

empreendedoras: construindo a ponte entre clima interno e desempenho superior. $363 \mathrm{f}$. Tese de doutorado. EAESP/FGV, São Paulo, junho, 2009.

HENISZ, W. J.; ZELNER; B. A.; GUIKKÉN, M. F. The world-wide diffusion of market-oriented infrastructure reform, 1977-1999. American Sociological Review, EUA. v. 70, n. 6, p. 871-897, 2005.

HIGGINS, B. H. Economic development: principles, problems, and policies. Nova York: Norton, 1959.

HISRICH, R. D.; PETERS, M. P. Empreendedorismo. 5. ed. Porto Alegre: Bookman, 2004.

HOLANDA, S. B. de. Raízes do Brasil. São Paulo: Brasiliense, 2000.

HOOD, C. A Public Management for all Seasons? Public Administration, EUA, v. 69, n.1, p.3-19, 1991.

IMASATO, T.; MARTINS, P. E. M.; PIERANTI, O. P. Administrative reforms and global managerialism: a critical analysis of three brazilian state reforms. Canadian journal of Administrative Sciences, Canada. 2011.

JANOTTI, M. de L. M. O coronelismo: uma política de compromissos. 6. ed. São Paulo: Brasiliense, 1987.

KEARNEY, C.; HISRICH; R.; ROCHE, F. Facilitating public sector corporate entrepreneurship process: a conceptual model. Journal of Enterprising Culture, Singapore, v. 15 , n. 3, p. 275-99, 2007.

Public and private sector entrepreneurship:

Similarities, differences or a combination? Journal of small business and enterprise development, United Kingdom, v. 16, n. 1, p. 26-46, 2009.

KETTL, D. F. A revolução global: reforma da administração do setor público. In: BRESSERPEREIRA, L. C; SPINK, P. (Org.). Reforma do estado e administração pública gerencial. Rio de Janeiro: FGV, 2006. p. 75-122.

KIHLSTROM, R. E.; LAFFONT, J. J. A general equilibrium entrepreneurial theory of firm formation based on risk aversion. Journal of Political Economy, EUA, v. 87, n. 4, p. 719-748, 1979.
KLEIN, N. A doutrina do choque: a ascensão do capitalismo de desastre. Rio de Janeiro: Nova Fronteira, 2008.

KLEIN, P. G. et al. Toward a theory of public entrepreneurship. European Management Review, v. 7, n. 1, p. 11-15, 2010.

LUMPKIN, G. T.; DESS, G. G. Clarifying the entrepreneurial orientation construct and linking it to performance. Academy of Management Review, EUA. v. 21, n. 1, p. 135-172, 1996.

LUSTOSA DA COSTA, F. Brasil: 200 anos de Estado; 200 anos de administração pública; 200 anos de reformas. Revista de Administração Pública, Rio de Janeiro. v. 42, n. 5, p. 829-887, 2008.

Reforma do estado e contexto brasileiro: crítica do paradigma gerencialista. Rio de Janeiro: FGV, 2010.

MCCLELLAND, D. C. The Achieving Society. Nova York: Irvington Publishers, 1961.

MATIAS-PEREIRA, J. Curso de Administração Pública: foco nas instituições e ações governamentais. 2. ed. São Paulo: Atlas, 2009.

MATTA, R. da. Carnavais, malandro e heróis: para uma sociologia do dilema brasileiro. 2. ed. Rio de Janeiro, Zahar, 1980.

MEYNHARDT, T.; DIEFENBACH, F. E. What drives entrepreneurial orientation in the public sector? Evidence from Germany's Federal Labor Agency. Journal of Public Administration Research Theory, United Kingdom, v. 22, n. 4, p. 761-792, 2012.

MILLER, D. The correlates of entrepreneurship in three types of firms. Management Science, EUA, v. 29, n. 7, p. 770-791, 1983.

MILLER, D.; FRIESEN, P. H. Strategy-making and environment: The third link. Strategic Management Journal, United Kingdom, v. 4, n. 3, p. 221-235, 1983.

MISOCZKY, M. C. Sobre o centro, a crítica e a busca de liberdade na práxis acadêmica. Cadernos EBAPE.BR, Rio de Janeiro, v. 4, n. 3, p. 1-13, out. 2006. 
MOORE, M. Creating Public Value: Strategic

Management in Government. Cambridge, MA: Harvard University Press, 1995.

MORRIS, M. H.; KURATKO, D. F.; COVIN, J. G.

\section{Corporate entrepreneurship and innovation:}

entrepreneurial development within organizations (2nd ed.). Mason, OH: Thomson/South-Western, 2008.

MORRIS, M. H.; JONES, F. F. Entrepreneurship in established organizations: The case of the public sector.

Entrepreneurship Theory and Practice, EUA. v. 24, n. 1, p. 71-91, 1999.

NUNES, E. A gramática política do Brasil: clientelismo, corporativismo e insulamento burocrático. Rio de Janeiro: Garamond, 2010.

OSBORNE, D.; GAEBLER, T. Reinventando o governo: como o espírito empreendedor está transformando o setor público. Brasília, DF: MH Comunicação, 1994.

PAES DE PAULA, A. P. Por uma nova gestão pública: limites e potencialidades da experiência contemporânea. Rio de Janeiro: FGV, 2005.

PINCHOT III, G. Intrapreneuring: porque você não precisa deixar a empresa para tornar-se um empreendedor. São Paulo: Harbra, 1985.

POLLITT, C. Is the Emperor in His Underwear? $\mathrm{Na}$ Analysis of the Impacts of Public Management Reform, Public Management, EUA, v. 2, n. 2, p. 181-199, 2000.

RAADSCHELDERS, J. C. N. What are "great books" in the study of public administration? Some polemic thoughts about the surveys of Sherwood and Kasdan. Administration \& Society, EUA, v. 44, n. 7, p. 894-904, 2012.

RAMAMURTI, R. Public entrepreneurs: Who they are and how they operate. California Management Review, California, v. 28, n. 3, p. 142-158, 1986.

\section{RAINEY, H. G. Understanding and managing public} organizations. (4th ed.). San Francisco, CA: Jossey-Bass, 2009.

RAUCH, A.; et al. Entrepreneurial orientation and business performance: an assessment of past research and suggestions for the future. Entrepreneurship Theory and Practice, EUA, v. 33, n. 3, p. 761-787, 2009.
RAMOS, A. G. A redução sociológica. 2. ed. corrigida e aumentada. Rio de Janeiro: Coleção Tempo Novo, 1965.

ROBERTS, N. C.; KING, P. J. Policy entrepreneurs: Their activity structure and function in the policy process.

Journal of Public Administration Research and Theory, United Kingdom, v. 1, n. 2, p. 147-175, 1991.

ROBERTS, N. C. Public entrepreneurship and innovation. Policy Studies Review, EUA, v. 11, n. 1, p. 55-74, 1992.

SADLER, R. J. Corporate entrepreneurship in the public sector: the dance of the chameleon. Australian Journal of Public Administration, Australia, v. 59, n. 2, p. 2543, 2000.

SCHUMPETER, J. A. History of economic analysis. Nova York: Oxford University Press, 1954.

SCHNEIDER, M.; TESKE, P. E.; MINTROM, M.

Public entrepreneurs: agents for change in American government. Princeton, NJ: Princeton University Press, 1995.

SCOTT, A. Bureaucratic revolutions and free market utopias. Economy and Society, California, v. 25, n. 1, p. 89-110, 1996.

SECCHI, L. Modelos organizacionais e reformas da administração pública. Revista de Administração Pública, Rio de Janeiro, v. 43, n. 2, p. 347-69, mar.-abr. 2009.

SERVA, M. A racionalidade substantiva demonstrada na prática administrativa. Revista de Administração de Empresas, São Paulo, v. 37, n. 2, p.18-30, 1997.

SHOCKLEY, G. E. et al. Toward a theory of public sector entrepreneurship. International Journal of Entrepreneurship and Innovation Management, EUA. v. 6, n. 3, p. 205-223, 2006.

SMITH, A. An Enquiry Into the Nature and Cause of the Wealth of Nations, Edwin Cannan, London. Also 1950, Methuen, London; 1963 Irwin, reedited in two volumes. See especially 1869, James E. Thorold Rogers, Clarendon Press, Oxford, 1766.

STEVENSON, H. H.; JARILLO, J. C. A paradigm of entrepreneurship: Entrepreneurial management. Strategic Management Journal, EUA, v. 11, p. 17-27, 1990. 
STOKER, G. Public value management: A new narrative for networked governance? The American Review of

Public Administration, EUA, v.36, n.1, p. 41-57, 2006.

TENÓRIO, F. Gestão Social: uma perspectiva social.

Revista de Administração Pública, Rio de Janeiro, v. 32, n. 5, p. 7-23, set.-out. 1998.

\section{TORRES, M. D. F. Estado, democracia e}

administração pública no Brasil. Rio de Janeiro: FGV, 2004.

VALADARES, J. L.; EMMENDOERFER, M. L.; SILVA, G. M. Modernização da Administração Pública de Minas Gerais: um Estudo exploratório do Cargo de Empreendedor Público. In: FERREIRA, M. A. M.; ABRANTES, L. A. (Org.). Políticas públicas, gestão e sociedade. Viçosa: Triunfal Gráfica e Editora, 2013.

VALADARES, J. L.; EMMENDOERFER, M. L. Cargos de livre nomeação: reflexões com base no empreendedor público em um estado-membro do Brasil. Revista de Administração Contemporânea, Curitiba, v. 16, n. 5, out. 2012.

VALADARES, J. L. et al. Brasil e Angola: convergências e divergências epistemológicas entre seus respectivos modelos de Administração Pública. Revista de Ciências de Administração, Florianópolis, v. 15, n. 36, p. 131142, ago. 2013.

VOGEL, R. Framing and Counter-Framing New Pubic Management: the case of Germany. Public Administration, EUA, v. 90, n. 2, p. 370-392, 2012.

WEBER, M. Economia e Sociedade. Brasília, DF: UnB, 1999.

ZAHRA, S. A. Predictors and financial outcomes of corporate entrepreneurship: An exploratory study. Journal of Business Venturing, EUA, v. 6, p. 259-285, 1991.

ZWICK, E. et al. Administração pública tupiniquim: reflexões a partir da Teoria $\mathrm{N}$ e da Teoria P de Guerreiro Ramos. Cadernos EBAPE.BR, Rio de Janeiro, v. 10, n. 2, jun. 2012. 